\title{
DISCAPACIDAD
}

\section{Políticas públicas y discapacidad en el Paraguay}

\author{
Rosa Ruffinelli , Stella García ${ }^{1}$
}

\begin{abstract}
Resumen
Introducción: Investigar temas referidos a la discapacidad nos sitúa por un lado ante personas con deficiencias en la mayoría de los casos con limitación física, mental o sensorial y por barreras que la misma sociedad les impone, que presentan en su mayoría altos grados de exclusión social, poco acceso a empleo, educación, accesibilidad a sitios públicos, entre otras desventajas sociales.
\end{abstract}

Objetivo: Analizar el origen y evolución de las políticas de Discapacidad en el Paraguay en el periodo de 1970 al 2006.

Material y Método: El estudio fue observacional, descriptivo con enfoque cualitativo, a partir de una revisión documental y entrevistas. Fueron realizadas 7 entrevistas en profundidad a personas con discapacidad militantes tanto de organizaciones del Estado como de la sociedad civil.

Resultados: La discapacidad ha sido tradicionalmente como un problema individual, que afecta a personas en particular, un problema derivado de la condición de cada una de las personas, y por lo tanto que debe ser resuelto en forma también individual y conforme a las condiciones que tienen las familias para resolver estas situaciones. En el caso de Paraguay no fue diferente, la discapacidad se mantuvo mucho tiempo invisible a la vida pública, solo enmarcada en el ámbito doméstico, y por lo tanto asumido y resuelto por este ámbito. Esto se evidencia en la revisión documental realizada en los planes de desarrollo de la Secretaría Técnica de Planificación del Desarrollo Económico y Social que desde su creación el 6 de marzo de 1962 (Ley №312/62), no registra información sobre discapacidad en los planes de desarrollo nacional. Recién en los años 70, según relata el Dr. Bonifacio Irala Amarilla "que, a partir de una situación particular con su hija, Tonia Bernardita" empieza a ver la necesidad de que las personas con discapacidad también requerían servicios y que el estado no le estaba brindando ninguna atención, es más estaba invisibilizando a esa población. La persona con discapacidad por su condición misma no era considerada sujeto de derecho, era invisible a toda la sociedad. Durante este primer periodo, como política social estaba tutelada por instituciones internacionales como el Instituto Interamericano del Niño, que y lo que se

1. Universidad Nacional de Asunción. Instituto de Trabajo Social.

Publicado en la Revista Kera Yvoty, Número 4, año 2018.

E-mail: rosaruffinelli@gmail.com

DOI: $10.26885 /$ rcei.foro.2018.32 


\section{Políticas públicas y discapacidad en el Paraguay. Ruffinelli \& García}

buscó prestar asistencia a las personas con discapacidad sin instalar un sistema de servicios que cubra todo el territorio nacional, es más fue acotado al área de Asunción y sus alrededores. Con el advenimiento de un proceso más democrático, se suponía que la realidad de las personas con discapacidad pudiera haberse modificado, pero no fue así, las organizaciones existentes comenzaron a buscar ingresos para el financiamiento de acciones, siempre tendientes a la rehabilitación, considerando el déficit con que se contaba en esta área, aun no enfocada en los derechos, sino más bien al cuidado de la salud y la rehabilitación. En el 2004 con esta nueva generación de políticas públicas, por primera vez aparece la protección social en el discurso del estado, pero de manera limitada a los programas de reducción de la pobreza, y trasverzalizada en ella la discapacidad, pero aun sin ser considerada, como una causa de la misma. En esta etapa se da la participación activa y permanente de las organizaciones de la sociedad civil que trabajan en el sector, pero la principal influencia hacia el estado viene de los organismos internacionales que presionan para la consolidación de instancias institucionales que rijan la temática a nivel nacional.

Conclusiones: Si bien la discapacidad como categoría de análisis es muy incipiente y más bien es vista desde las ciencias médicas, enarcadas en la anormalidad, esta primera aproximación visualiza que aun la visión desde las personas con discapacidad es desde la perspectiva médica, lo que refleja en las acciones y preocupaciones tanto de las personas con discapacidad, así como desde las respuestas del estado a las solicitudes de los mismos.

Palabras clave: discapacidad, políticas públicas, estado paraguayo.

\section{RefERENCIAS}

Comité Nacional de Coordinación sobre Discapacidades en el Paraguay. (1992). Documento de trabajo № 1. Asunción: documento no publicado.

Gómez Bernal, V. (2014). Análisis de la discapacidad desde una mirada crítica: las aportaciones de las teorías feministas. Estudios Pedagógicos, 40(2), 391-407.

Moreno Anganita, M. (2010). Infancia, políticas y discapacidad. Bogotá: Universidad Nacional de Colombia.

Torres Dávila, M. (2004). Discapacidad y Género: más allá del sentido de la maternidad diferente (Tesis de Maestría en Estudios de Género). Ecuador: FLACSO. 